\title{
Extended-Spectrum $\beta$-Lactamase Enzymes (ESBLs) Produced by Escherichia coli Urinary Pathogens at Riyadh, Saudi Arabia
}

\section{Al-Mijalli SHS ${ }^{*}$}

Biology Department, Scientific Section, Princess Norah Bent AbdulRahman University, Saudi Arabia

*Corresponding author: Samiah HS Al-Mijalli, Biology Department, Scientific Section, Princess Norah Bent AbdulRahman University, Riyadh, Saudi Arabia, Tel: +966118220000; E-mail: dr.samiah10@hotmail.com

Received: August 04, 2016; Accepted: August 31, 2016; Published: September 05, 2016

Copyright: (c) 2016 Al-Mijalli SHS. This is an open-access article distributed under the terms of the Creative Commons Attribution License, which permits unrestricted use, distribution, and reproduction in any medium, provided the original author and source are credited.

\begin{abstract}
Background: This study aim was to determine the probable type of $\beta$-lactamase gene which is responsible for resistance. It was found that OXA (701 bp) was the main type of $\beta$-lactamase (35.7\%), CTX-M (569 bp) was second $(28.9 \%)$, TEM (403 bp) was third $(20.5 \%)$ and SHV (293 bp) $(14.9 \%)$ was fourth.

The aim and objectives of this study were to investigate the prevalence of ESBLs producing in these bacteria isolated from uropathogenic out-patients and to look for the presence of TEM or SHV, CTX and OXA genes in E. coli.

Results: The present study was carried out from the Central Laboratory of Riyadh Hospital in Saudi Arabia from January 2014 to June 2015. Total 116 urine samples were tested bacteriologically and for antibiotic susceptibility using standard procedures, Detection of extended-spectrum $\beta$-lactamases and determination of the genotype of $\beta$ lactamase of $75 \mathrm{E}$. coli isolates by PCR: It was found that OXA (701 bp) was the main type of $\beta$-lactamase (35.7\%), CTX-M (569 bp) was second (28.9\%), TEM (403 bp) was third (20.5\%) and SHV (293 bp) $(14.9 \%)$ was fourth.

Conclusions: This study showed that the ESBL producing isolates detected PCR with oligonucleotide primers of TEM, SHV, and CTX-M and OXA genes and were carried out on E. coli DNA of 75 isolates. PCR, incorporating the primers for commonly prevalent ESBLs may be a valuable clinical and research tool for characterization of ESBLs.
\end{abstract}

Keywords: Urinary tract; Infections; Outpatients; Antibiotic susceptibility; $\beta$-lactamase; PCR

\section{Introduction}

Urinary tract infections (UTI) are one of the most common infectious diseases diagnosed [1]. ESBLs have become widespread throughout the world and are now found in a significant percentage of Escherichia coli and Klebsiella pneumonia strains in certain countries [2]. Worldwide data show that there is increasing resistance among urinary tract pathogens to conventional drugs. E. coli isolates from both community and hospital infections were highly susceptible to many antimicrobial agents with the exception of those isolates producing extended spectrum $\beta$-lactamases (ESBLs) [3]. ESBL isolates are prevalent in developing countries and multiple resistant to gentamicin, ciprofloxacin, tetracycline, sulfamethoxazole/ trimethoprim. They are inhibited by clavulanate (CA), sulbactam, or tazobactam [4]. More than $90 \%$ of ESBL-producing organisms were "susceptible" to cephamycins [5]. The use of cefepime to treat serious nosocomial infections (e.g., bacteremia, pneumonia, and urinary tract infections) is associated with high rates of microbiological and clinical success [6]. Treatment of extended spectrum beta-lactamase (ESBL) producing strains of Enterobacteriaceae has emerged as a major challenge in hospitalized as well as community-based patients [7].

The importance of molecular diagnostics will increase, as they are a more reliable method than phenotypic testing [8]. Plasmid mediated lactamase producing isolates of the family Enterobacteriaceae and mainly possessed the blaTEM (Temoneira) and the blaCTX-M (Cefotaximase Munchen) genes [9]. There are so many types of ESBLs like TEM, SHV, CTX, OXA, AmpC, etc. but the majority of the ESBLs are derivatives of TEM or SHV enzymes and these enzymes are most often found in E. coli and $K$. pneumonia [10]. OXA $\beta$-lactamases were long recognized as a less common but also a plasmid-mediated $\beta$ lactamase variety that could hydrolyze oxacillin and related antistaphylococcal penicillins. These $\beta$-lactamases differ from the TEM and SHV (Sulphydryl variable) enzymes in that they belong to molecular class $\mathrm{D}$ and functional group $2 \mathrm{~d}$. The OXA-type $\beta$ lactamases confer resistance to ampicillin and cephalothin and are characterized by their high hydrolytic activity against oxacillin and cloxacillin and the fact that they are poorly inhibited by clavulanic acid [7].

The current study was investigated upon the prevalence of ESBLs producing in these bacteria isolated from uropathogenic out-patients and to look for the presence of TEM or SHV, CTX and $O X A$ genes in E. coli.

\section{Materials and Methods}

\section{Sample collection}

Fresh midstream urine samples were collected from female patients 70 (60.34\%) samples and 46 (39.66\%) from male patients. Adult patients were sampled by clean catch midstream urine [11] and children aged less than 3 years were sampled using sterile urine bags. 


\section{Data collection}

Data were conducted by a questionnaire consisting of short-answer questions including, dates, bacterial agents (first, second and third pathogen), diagnostic techniques, sex and age of patients, predisposing factors and mortality [12]. In the present study, the patients who referred to the Laboratory Center of Riyadh Hospital were studied, for a period of (January 2015 to June 2015).

\section{Isolation and identification of organisms}

The urine samples were mixed thoroughly, centrifuged and examined microscopically for wet mount preparation. This was followed by a Gram's stain. Samples for urine culture were tested within half an hour of sampling. All samples were inoculated on blood agar as well as Mac Conkey agar and incubated at $37^{\circ} \mathrm{C}$ for $24 \mathrm{~h}$, and for $48 \mathrm{~h}$ in negative cases. A specimen was considered positive for UTI in the light of the number of yielded colonies $(\geq 105 \mathrm{cfu} / \mathrm{mL})$ and the cytology of the urine through microscopic detection of bacteriuria and PMNs ( $\geq 8$ leukocytes $/ \mathrm{mm}^{3}$ ). However, lower colony counts associated with significant pyuria or low PMN count associated with significant colony counts was considered and analyzed in the light of the clinical picture and the patient's immunological status. Bacterial identification was based on standard culture and biochemical characteristics of isolates [13-15].

\section{Bacterial identification}

It was made using biochemical tests, namely indole, citrate, oxidase, $\mathrm{H}_{2} \mathrm{~S}$ production, lysine decarboxylase, lactose fermentation, urea hydrolysis, gas production, catalase, coagulase, mannitol fermentation and novobiocin susceptibility test cystine lactose.

Electrolytes deficiency agar (CLED), analytical profile index (API) and Mueller-Hinton agar (MH).

\section{Antimicrobial susceptibility testing by modified kirby-bauer disc diffusion method}

Antibiotic susceptibility was done on Mueller-Hinton agar using disk diffusion (Kirby Bauer's) method according to the Clinical and Laboratory Standards Institute (CLSI) guidelines using the following 21 antimicrobial agents: amikacin $(30 \mu \mathrm{g})$, gentamicin $(10 \mu \mathrm{g})$, ciprofloxacin $(5 \mu \mathrm{g})$, ertapenem $(30 \mu \mathrm{g})$, nitrofurantoin $(300 \mu \mathrm{g})$, imipenem $(30 \mu \mathrm{g})$, meropenem $(30 \mu \mathrm{g})$, trimethoprim/ sulfamethoxazole $(25 \mu \mathrm{g})$ [16], tigecycline $(30 \mu \mathrm{g})$, piperacillin/ tazobactam $(30 \mu \mathrm{g})$, levofloxacin $(30 \mu \mathrm{g})$, colistin, cephalothin, cefuroxim $(10 \mu \mathrm{g})$, ceftriaxon $(30 \mu \mathrm{g})$, ceftazidim $(30 \mu \mathrm{g})$, cefoxitin $(30$ $\mu \mathrm{g})$, cefepime $(30 \mu \mathrm{g})$, aztreonam $(30 \mu \mathrm{g})$, ampicillin $(10 \mu \mathrm{g})$ and amoxicillin $(30 \mu \mathrm{g})$ for all bacterial isolates (Table 1).

\begin{tabular}{|l|l|l|}
\hline Aztreonam & $($ ATM) & $30 \mu \mathrm{g}$ \\
\hline Ceftazidime & $($ CAZ) & $30 \mu \mathrm{g}$ \\
\hline Cefepime & $($ FEP $)$ & $30 \mu \mathrm{g}$ \\
\hline Cefotaxime & $($ CTX) & $30 \mu \mathrm{g}$ \\
\hline Cefpodoxime & $($ POD $)$ & $30 \mu \mathrm{g}$ \\
\hline
\end{tabular}

Table 1: Antibiotics screening test for ESBLs production (Double Disc Synergy test).
Augmentin (AU) $20 \mu \mathrm{g} / 10 \mu \mathrm{g}$, with cefotaxime (CTX) $30 \mu \mathrm{g} /$ cefpodoxime, aztreonam (ATM) $30 \mu \mathrm{g}$, ceftazidime (CAZ) $30 \mu \mathrm{g}$, and cefepime (FEP) $30 \mu \mathrm{g}$.

\section{ESBL-E test}

A total of 116 urine samples will be identified by using culture and sensitivity on CLED/API-strips and Mueller-Hinton agar respectively. The MICs of antibiotics were determined by the agar dilution method, as described in the National Committee for Clinical Laboratory Standards (NCCLS) guidelines, on Mueller-Hinton agar (bioMérieux). Two agar plates will be inoculated as described for the standard disc diffusion test. An inoculum of $104 \mathrm{cfu} / \mathrm{spot}$ was applied to antibioticcontaining plates with a multipoint inoculator (West Sussex Instruments Ltd., Denley, UK). Amoxycillin was combined with the clavulanic acid in a 2:1 ratio and the concentration of tazobactam in combinations with piperacillin was $4 \mathrm{mg} / \mathrm{L}$. The conventional doubledisc test with co-amoxiclav, ceftriaxone and ceftazidime were used to detect extended-spectrum $\beta$-lactamase (ESBL) production in Enterobacteriaceae strains. Isolates with MICs of $\geq 2 \mathrm{mg} / \mathrm{liter}$ for aztreonam, ceftazidime, cefoxitin, cefotaxime and/or cefepime were checked for ESBL production by the double-disk synergy test and the E-test (AB Biodisc). For these assays, E. coli ATCC 25922 and $K$. pneumonia ATCC 700603 were included as quality control strains. In each plate, four $30 \mu \mathrm{g}$ discs (aztreonam, ceftazidime, cefoxitin, cefotaxime and/or cefepime) were placed at inner disc distances (center to center) of $25 \mathrm{~mm}$ or $30 \mathrm{~mm}$ away from an amoxicillin/ clavulanic acid disc $(20 \mu \mathrm{g} / 10 \mu \mathrm{g})$. A clear extension of the edge of the inhibition zone towards the disc containing clavulanic acid will be interpreted as positive for ESBL production. The organisms will be tested against $3^{\text {rd }}$ and $4^{\text {th }}$ generation cephalosporins (aztreonam, ceftazidime, cefpodoxime, cefotaxime and lor cefepime and amoxiclav) and a second generation cephalosporins (cefoxitin) for confirmation of ESBL producer organism. The MICs which were considered to indicate susceptibility $\leq 4 \mu \mathrm{g} / \mathrm{ml}$ to $8 \mu \mathrm{g} / \mathrm{ml}$ were interpreted as susceptible, $=16$ $\mu \mathrm{g} / \mathrm{ml}$ were interpreted as intermediate results and $>16$ were interpreted as resistant results for cefepime, cefoxitin and ceftazidime. Among, cefotaxime, aztreonam, and cefpodoxime were $=2,=8$ and $=4$ interpreted as intermediate results respectively. Also, the results interpreted as resistant were $>$ or $=4,16$ and 8 respectively.

Sampling: Sample frame: UTI patients with urosepsis.

Study duration: January 2014 to June 2015.

\section{Validity and pre-testing}

- The sterility and the efficiency of the culture media will be tested by incubating $5 \%$ of plates aerobically overnight at $37^{\circ} \mathrm{C}$ then check for growth.

- Control strains will be examined for growth on culture and sensitivity media.

- All reagents will be pre-tested using control strains and equipment will be calibrated Table 2 .

\begin{tabular}{|l|l|}
\hline Proteinase $\mathrm{k}$ & $5 \mathrm{~g}$ \\
\hline dNTPs & 3000 units \\
\hline Tag polymerase & 3000 units \\
\hline Primers (specify) & 3000 units for each \\
\hline $\mathrm{MgCl}_{2}$ (PCR buffer) & \\
\hline
\end{tabular}


Page 3 of 9

\begin{tabular}{|c|c|}
\hline \multicolumn{2}{|l|}{ Electrophoresis reagents } \\
\hline Agarose high grade & $500 \mathrm{~g}$ \\
\hline Ethidium bromide & $5 \mathrm{~g}$ \\
\hline Xylene cyanol & $25 \mathrm{~g}$ \\
\hline \multicolumn{2}{|c|}{ Primers for the following genes of beta-lactamases resistance } \\
\hline Tem beta-Lactamases & (class A) \\
\hline SHV beta-Lactamases & (class A) \\
\hline CTX-M beta-Lactamases & (class A) \\
\hline QXA beta-Lactamases & (class D) \\
\hline
\end{tabular}

Table 2: Reagents.

\section{Quality control}

The quality controls strains will be used for ESBLs testing are $K$. pneumoniae ATCC700603 as positive control and E. coli ATCC 25922 as a negative control. Mistakes must be checking in data entry.

Detection of extended spectrum $\beta$-lactamases: Selective testing for ESBL production was considered for all E. coli 75 (75\%) isolates.

\section{Plan of data analysis}

The software will be used for analysis Statistical Package for Social Sciences (SPSS) program, for categorical variables proportions will be compared by the chi-square test as appropriate.

\section{DNA extraction, PCR and sequencing}

A single colony from each ESBL producing isolate was transferred into $100 \mu \mathrm{L}$ of distilled water and the bacterial DNA was extracted by using a commercial DNA extraction kit. Bacterial genes associated with antimicrobial resistance phenotypes were detected by PCR amplification of target genes by using specific PCR primers (Table 3). The boiling method was used to extract DNA from bacterial samples [17]. TEM, SHV, CTX-M and OXA $\beta$ lactamase genes were detected by a method using specific oligonucleotide primers to determine blaTEM, blaSHV, blaCTX-M and blaOXA genes. Primer sequences and their size were used for the detection of blaTEM, blaSHV, blaCTX-M and blaOXA genes in this study, which is listed in Table 3.

\begin{tabular}{|c|c|c|c|c|}
\hline Primers & ${ }^{\circ} \mathrm{C}$ & Nucleotide seq. $\left(5^{\prime}-3^{\prime}\right)$ & Ref (GenBank No) & Exp. Ampl size (bp) \\
\hline SHV-F & 60 & CGCCTGTGTATTATCTCCCT & \multirow[t]{2}{*}{ EF125011 } & \multirow[t]{2}{*}{293} \\
\hline SHV-R & 62 & CGAGTAGTCCACCAGATCCT & & \\
\hline TEM-F & 60 & TTTCGTGTCGCCCTTATTCC & \multirow[t]{2}{*}{ AB282997 } & \multirow[t]{2}{*}{403} \\
\hline TEM-R & 62 & ATCGTTGTCAGAAGTAAGTTGG & & \\
\hline CTX-M-F & 60 & CGCTGTTGTTAGGAAGTGTG & \multirow[t]{2}{*}{ DQ303459 } & \multirow[t]{2}{*}{569} \\
\hline CTX-M-R & 62 & GGCTGGGTGAAGTAAGTGAC & & \\
\hline OXA-F & 64 & ATGGCGATTACTGGATAGATGG & \multirow[t]{2}{*}{ L07945 } & \multirow[t]{2}{*}{701} \\
\hline OXA-R & 62 & AGTCTTGGTCTTGGTTGTGAG & & \\
\hline
\end{tabular}

Table 3: Oligonucleotides primers used for detection of $\beta$-lactamases genes.

PCRs were carried out using thermal cycler (BioRad, USA) in a total volume of $25 \mu \mathrm{l}$ containing $10 \mathrm{pmol}$ of each two pair of primers (Sigma, USA), $25 \mu \mathrm{mol}$ of dNTPs, $5 \mu \mathrm{l}$ of template DNA, $2.5 \mu \mathrm{l}$ of $10 \mathrm{X}$ Taq buffer [ $50 \mathrm{mM} \mathrm{KCl}, 10 \mathrm{mM}$ Tris- $\mathrm{HCl}$ (pH 8.3)], $2 \mathrm{mM} \mathrm{MgCl}_{2}$ and $2.5 \mathrm{U}$ of Taq polymerase (Fermentas, USA). The Primer sequences and cycling conditions used for two different PCRs are shown in Table 3. PCR products were separated by gel electrophoresis on $1 \%$ agarose gel. In order to confirm the accuracy of genes amplified in this study, a PCR product of each gene was sent for sequencing to the Macrogen Company (South Korea) and the result was confirmed by NCBI Blast Tool.

PCR amplification of bla genes, including blaTEM, blaSHV, blaCTX-M and bla OXA was performed with Taq master mix DNA polymerase using primers listed in Table 3, under the following conditions.
Initial denaturation step at $95^{\circ} \mathrm{C}$ for $10 \mathrm{~min}$; 30 cycles of denaturation at $94^{\circ} \mathrm{C}$ for $30 \mathrm{~s}$, annealing at $60^{\circ} \mathrm{C}$ forward and $62^{\circ} \mathrm{C}$ reversal for $30 \mathrm{~s}$ for $T E M / S H V / C T X-M$ genes and for $O X A$ gene at $64^{\circ} \mathrm{C}$ forward and $62^{\circ} \mathrm{C}$ reversal, extension at $72^{\circ} \mathrm{C}$ for $2 \mathrm{~min}$, followed by a final extension step at $72^{\circ} \mathrm{C}$ for $10 \mathrm{~min}$. Respective genes were detected by the size separation-PCR amplicons by agarose gel electrophoresis.

\section{Results}

Out of 116 urine samples were collected from outpatients with urosepsis in Central Laboratory of Riyadh hospital in Saudi Arabia, during the period from January 2014 to June 2015 (Tables 1 and 2). There were $70(60.34 \%)$ females and $46(39.66 \%)$ males. The most commonly isolated organism was Escherichia coli $91(78.45 \%),\{58$ (50\%) from females and 33 (28.45\%) males\}, Table 4. 
Citation: Al-Mijalli SHS (2016) Extended-Spectrum $\beta$-Lactamase Enzymes (ESBLs) Produced by Escherichia coli Urinary Pathogens at Riyadh, Saudi Arabia. J Antimicrob Agents 2: 125. doi:10.4172/2472-1212.1000125

Page 4 of 9

\begin{tabular}{|l|l|l|l|l|l|l|}
\hline Sex & Female & \multicolumn{3}{l|}{ Male } \\
\hline Group & Children & Young & Adult & Children & Young & Adult \\
\hline Total count of 91(90 ESBL E. coli) & 16 & 18 & 24 & 9 & 5 & 19 \\
\hline $78.45 \%$ & 13.79 & 15.52 & 20.69 & 7.76 & 4.31 & 16.38 \\
\hline
\end{tabular}

Table 4: Total count of ESBL E. coli isolates on outpatients groups. ESBL E. coli (58 females and 23 males).

\section{Antimicrobial susceptibility testing}

Escherichia coli showed high susceptibility $(98.90 \%)$ to each of amikacin, meropenem, imipenem, ertapenem and colistin. While, $E$. coli exhibited resistance to ampicillin, aztreonam, cefepime, ceftriaxone, cefuroxime, cephalothin, ceftazidime and amoxicillin.

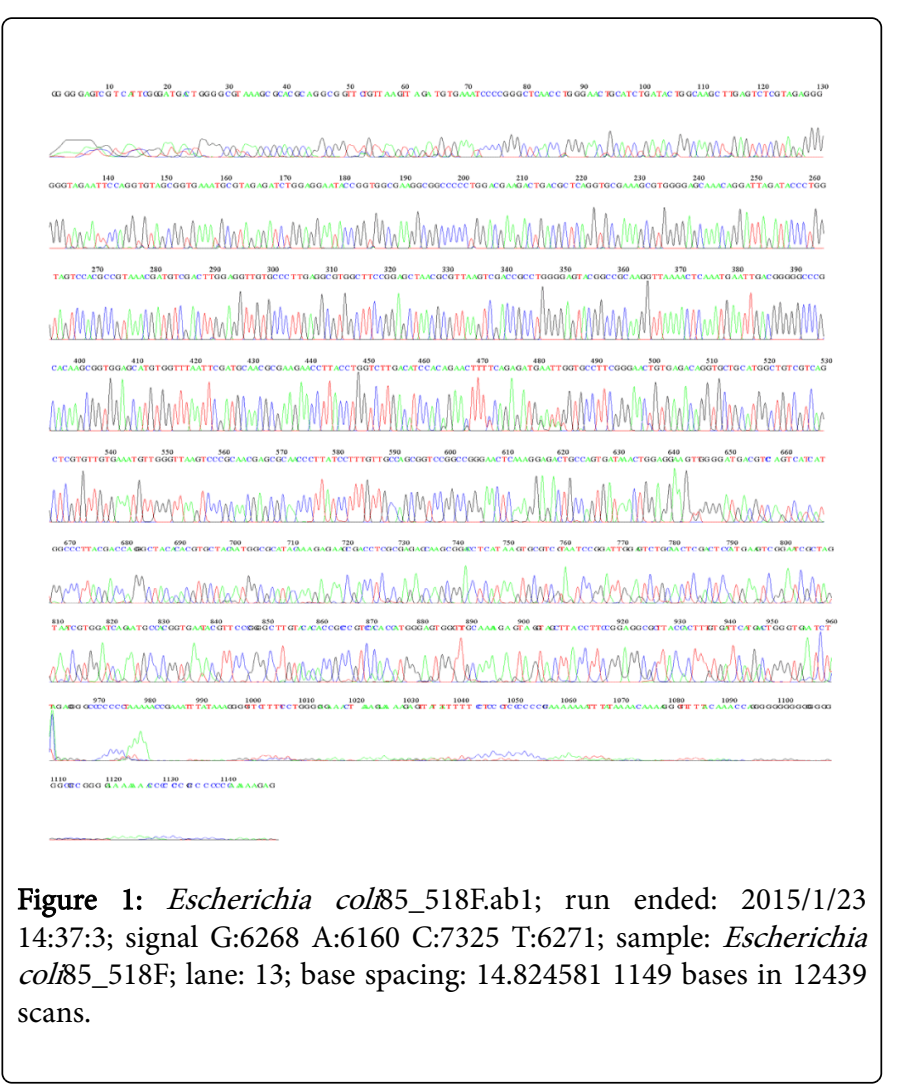

\section{Detection of extended-spectrum $\beta$-lactamases}

The percentage of ESBL producing isolates which were reported as sensitive ( $\mathrm{S}$ ) or intermediate (I) and resistant (R) to cephalosporins were determined, Table 4 . The current results showed that $90(78.45 \%)$ of isolated $E$. coli were ESBLs producing organisms. These isolates were identified as ESBL-producers and were resistant (R) to $\beta$-lactams: ampicillin, cefazolin, ceftriaxone (MIC $>64 \mu \mathrm{g} / \mathrm{ml})$, aztreonam, and piperacillin. After an ESBL confirmatory test, recommended by the Clinical and Laboratory Standards Institute CLSI [18,19] showed positive results, the isolates of the present study were also considered resistant to cefotaxime, aztreonam $>$ or $=4,16$ and (MIC $16 \mathrm{~g} / \mathrm{mL}$ ) to cefepime.
Disk diffusion method in this study indicated of high susceptibility to cefoxitin. The ESBL producing E. coli strains would have been reported as sensitive for cefoxitin (87.78\%), ceftazidime (46.67\%), cefepime $(31.11 \%)$ and for cefotaxime $(5.56 \%)$. But, as intermediate for ceftazidime (21.11\%), cefepime (18.89\%), cefoxitin (12.22\%), aztreonam $(8.89 \%)$ and for cefotaxime $(2.2 \%)$. Isolates were resistant for each of cefotaxime (92.22\%), aztreonam (74.44\%) and cefepime $(50 \%)$ respectively (Table 5$)$.

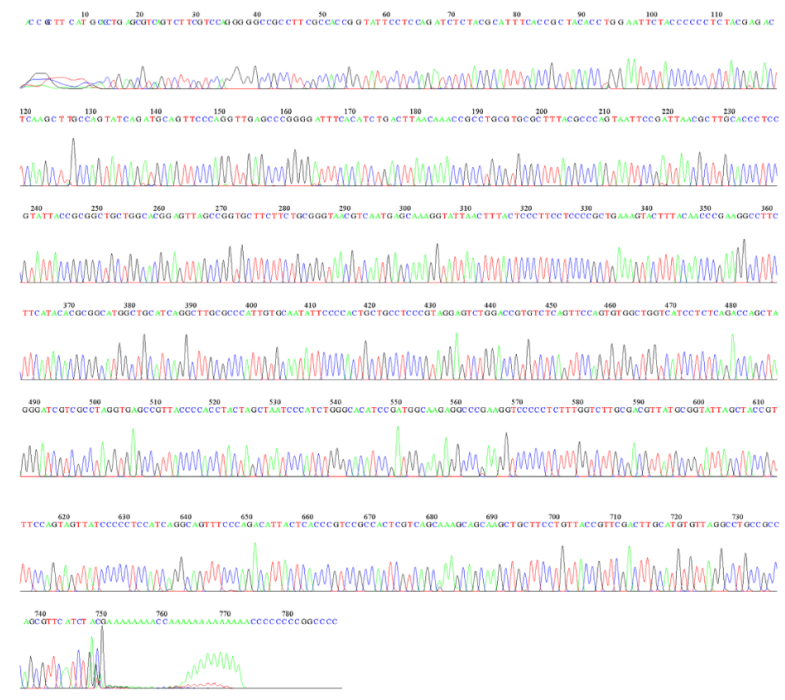

Figure 2: Escherichia coli86_800R.ab1; run ended: 2015/1/23 14:37:3; signal G:7019 A:7066 C:11734 T:9392; sample: Escherichia coli86_800R; lane: 11; base spacing: 14.874157788 bases in 9638 scans.

\begin{tabular}{|l|l|l|l|}
\hline Drug & Sensitive & Intermediate & Resistant \\
\hline Cefoxitin & $79(87.78 \%)$ & $11(12.22 \%)$ & -- \\
\hline Aztreonam & $15(16.67 \%)$ & $8(8.89 \%)$ & $67(74.44 \%)$ \\
\hline Cefotaxime & $5(5.56 \%)$ & $2(2.22 \%)$ & $83(92.22 \%)$ \\
\hline Ceftazidime & $42(46.67 \%)$ & $19(21.11 \%)$ & $29(32.22 \%)$ \\
\hline Cefepime & $28(31.11 \%)$ & $17(18.89 \%)$ & $45(50 \%)$ \\
\hline
\end{tabular}

Table 5: Susceptibility profiles of 90 ESBL-producing E. coli isolates. 
Citation: Al-Mijalli SHS (2016) Extended-Spectrum $\beta$-Lactamase Enzymes (ESBLs) Produced by Escherichia coli Urinary Pathogens at Riyadh, Saudi Arabia. J Antimicrob Agents 2: 125. doi:10.4172/2472-1212.1000125

Page 5 of 9

\section{Determination of the genotype of $\beta$-lactamase by PCR} 3.

The results of ESBL genotyping are shown in Figures 1-8 and Table

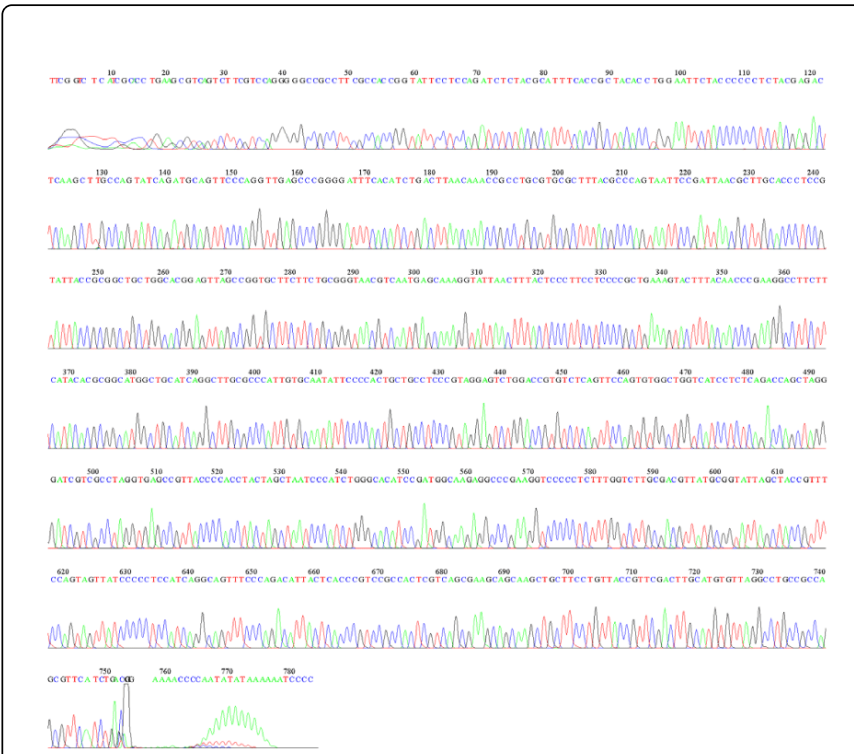

Figure 3: Escherichia coli95_800R.ab1; run ended: 2015/1/23 14:37:3; signal G:6199 A:6516 C:10597 T:8806; sample: Escherichia coli95_800R; lane: 9; base spacing: 14.864491784 bases in 9521 scans page.

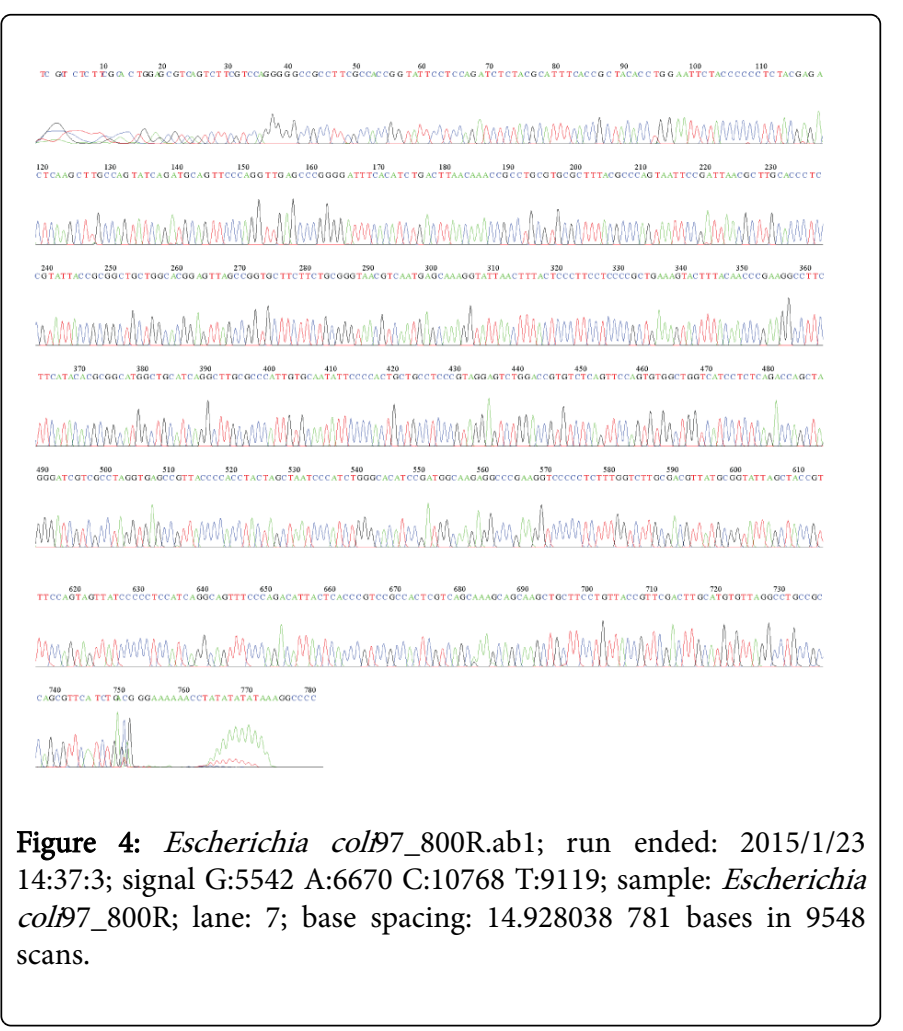

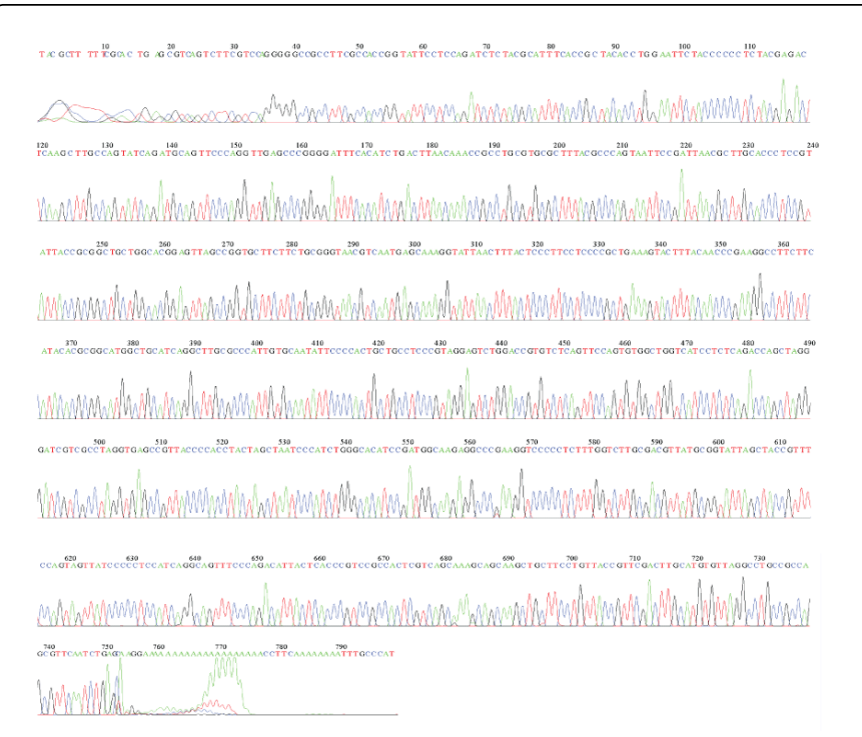

Figure 5: Escherichia coli99_800R.ab1; run ended: 2015/1/23 14:37:3; signal G:3742 A:4552 C:7592 T:6389; sample: Escherichia coli99_800R; lane: 5; base spacing: 15.029872799 bases in 9700 scans.

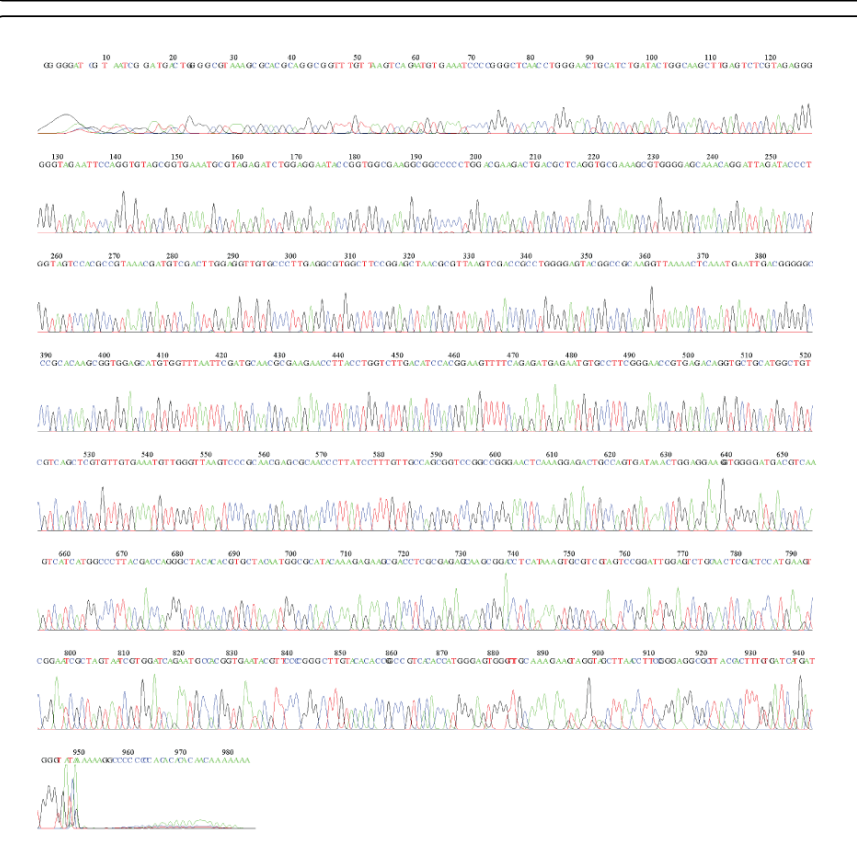

Figure 6: Escherichia coli100_518F.ab1; run ended: 2015/1/23 14:37:3; signal G:6276 A:9019 C:11357 T:9421; sample: Escherichia coli100_518F; lane: 3; base spacing: 15.031499984 bases in 10922 scans.

DNA of $E$. coli isolates (75\%) were analyzed by PCR. A total of $75 / 100(75 \%)$ of $E$. coli isolates were confirmed to be ESBL producers. Our aim was to determine the probable type of $\beta$-lactamase gene which is responsible for resistance. 
Citation: Al-Mijalli SHS (2016) Extended-Spectrum $\beta$-Lactamase Enzymes (ESBLs) Produced by Escherichia coli Urinary Pathogens at Riyadh, Saudi Arabia. J Antimicrob Agents 2: 125. doi:10.4172/2472-1212.1000125

Page 6 of 9

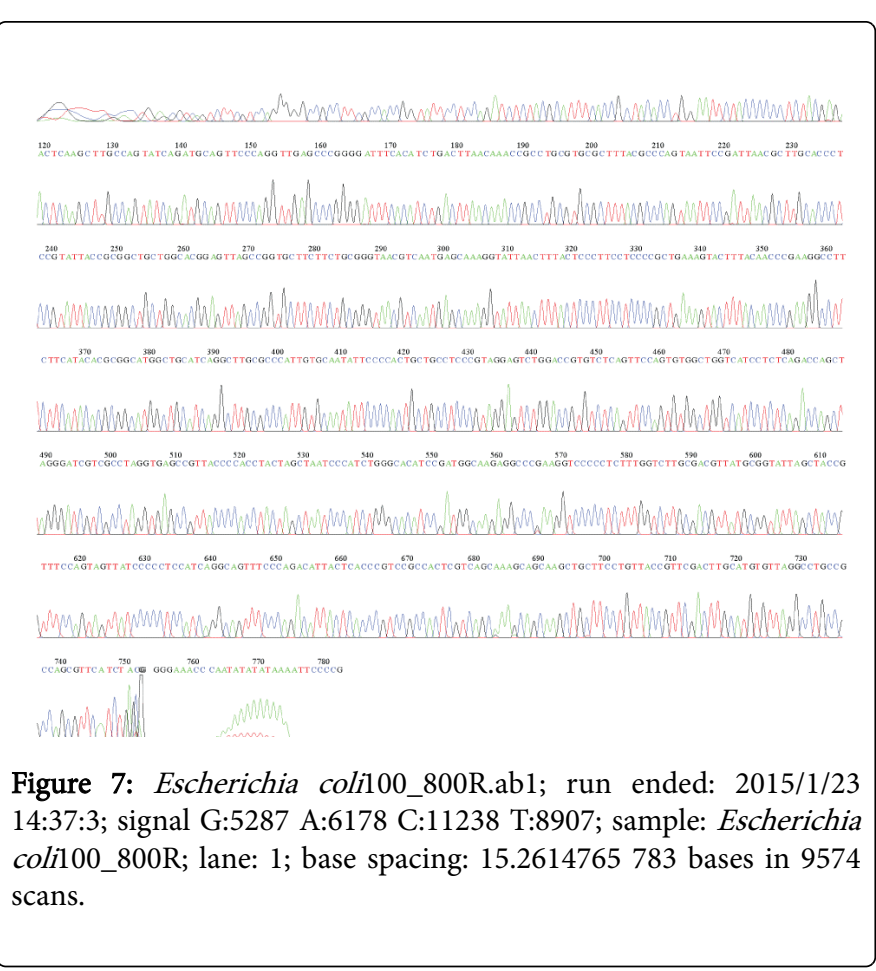

Bacterial species (50 spp.) used for specificity testing of speciesspecific primers Table 6. The results reveal that 38 (50.67\%) E. coli genomes used in the design of E. coli-specific primers Table 7.

Identification of clinical isolates to the species level was performed on three automated identification systems; the Vitek 2 (bioMerieux, Durham, NC), the BD Pheonix (diagnostics systems, sparks, MD), and the Microscan Walkway (Siemens Healthcare Diagnostics Inc., Deerfield, IL).

It was found that $O X A(701 \mathrm{bp})$ was the main type of $\beta$-lactamase (35.7\%), CTX-M (569 bp) was second (28.9\%), TEM (403 bp) was third (20.5\%) and $S H V(293 \mathrm{bp})$ (14.9\%) was fourth Table 3.

Also, eight strains of $E$. coli with run ended 14:37:3 and lanes 7, 1, 9, 11, 15 with 781 bp, 783 bp, 784 bp, 788 bp, 791 bp but lane 3 was 984 bp and lane 13 was 1149 bp as shown in Figures 1-8.

\begin{tabular}{|l|l|}
\hline Strain & Designation \\
\hline Acinetobacter baumannii & ATCC 19606 \\
\hline Acinetobacter lwoffi & Clinical isolate \\
\hline Achromobacter xylosoxidans & Clinical isolate \\
\hline Aeromonas hydrophilia & Clinical isolate \\
\hline Aeromonas veronii & Clinical isolate \\
\hline Bacillus subtilis & ATCC 6633 \\
\hline Burkholderia cepacia & ATCC 25416 \\
\hline Citrobacter freundii & ATCC 8090 \\
\hline Citrobacter koseri & Clinical isolate \\
\hline Clostridium difficile & ATCC 43255 \\
\hline
\end{tabular}

\begin{tabular}{|c|c|}
\hline Enterobacter aerogenes & ATCC 13048 \\
\hline Enterobacter cloacae & ATCC 13047 \\
\hline Enterobacter gergoviae & Clinical isolate \\
\hline Escherichia coli & ATCC 35218 \\
\hline Escherichia coli 0157 & ATCC 43888 \\
\hline Enterococcus casse & Clinical isolate \\
\hline Enterococcus faecalis & ATCC 51299 \\
\hline Enterococcus faecium & Clinical isolate \\
\hline Enterococcus gallinarium & ATCC 24311 \\
\hline Haemophilus influenzae & ATCC 10211 \\
\hline Hafnia alvei & ATCC 51873 \\
\hline Klebsiella oxytoca & Clinical isolate \\
\hline Klebsiella pneumoniae & ATCC 138 \\
\hline Kluyvera ascorbata & Clinical isolate \\
\hline Micrococcus luteus & ATCC 53 \\
\hline Moraxella osloensis & ATCC 10973 \\
\hline Morganella morganii & Clinical isolate \\
\hline Neisseria meningitidis & ATCC 53415 \\
\hline Pasteurella multocida & Clinical isolate \\
\hline Proteus mirabilis & ATCC 12453 \\
\hline Pseudomonas aeruginosa & ATCC 27853 \\
\hline Pseudomonas flourescens & ATCC 13525 \\
\hline Pseudomonas putida & Clinical isolate \\
\hline Pseudomonas stutzeri & Clinical isolate \\
\hline Providencia rettgeri & Clinical isolate \\
\hline Providencia stuartii & MRSN 2154 \\
\hline Serratia marcesens & ATCC 43861 \\
\hline Salmonella typhi & ATCC 14028 \\
\hline Shigella flexneri & ATCC 12022 \\
\hline Staphylococcus aureus & BAA 976 \\
\hline Staphylococcus capitis & Clinical isolate \\
\hline Staphylococcus hemolyticus & Clinical isolate \\
\hline Staphylococcus epidermidis & ATCC 12228 \\
\hline Staphylococcus saprophyticus & ATCC 15305 \\
\hline Streptococcus agalactiae & ATCC 12380 \\
\hline Streptococcus pyogenes & ATCC 19615 \\
\hline Streptococcus pneumoniae & ATCC 4969 \\
\hline Streptococcus sanguis & ATCC 10556 \\
\hline
\end{tabular}


Citation: Al-Mijalli SHS (2016) Extended-Spectrum $\beta$-Lactamase Enzymes (ESBLs) Produced by Escherichia coli Urinary Pathogens at Riyadh, Saudi Arabia. J Antimicrob Agents 2: 125. doi:10.4172/2472-1212.1000125

Page 7 of 9

\begin{tabular}{|l|l|}
\hline Streptococcus salivaius & ATCC 13419 \\
\hline Stenotrophomonas maltocida & Clinical isolate \\
\hline
\end{tabular}

Table 6: Bacterial species (50 spp.) used for specificity testing of species-specific primers.

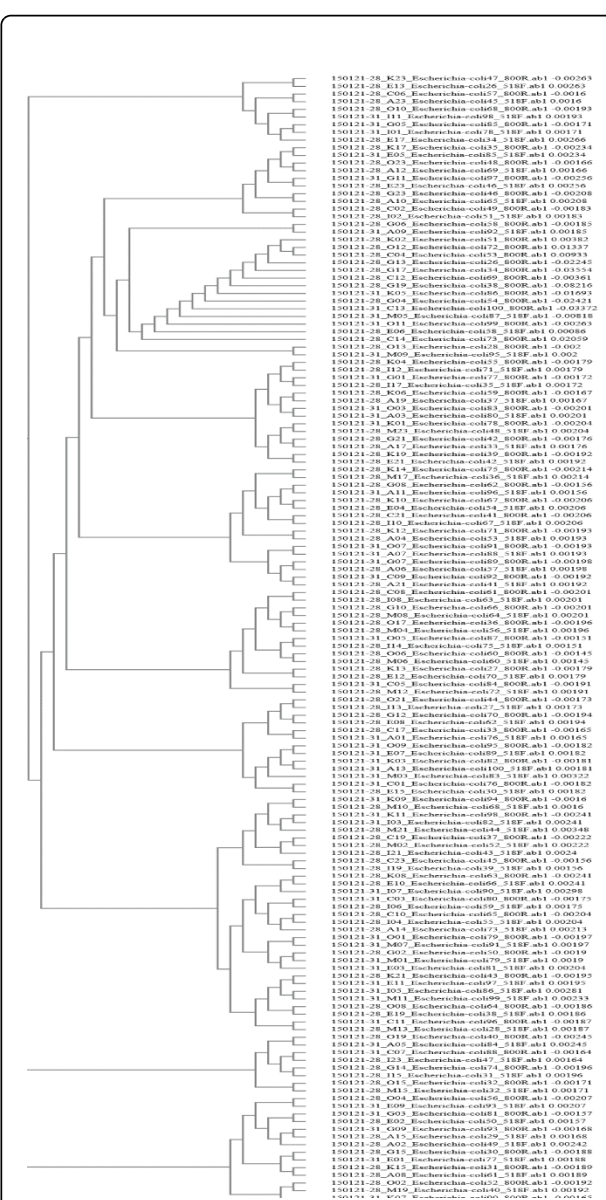

Figure 8: E. coli tree.

\begin{tabular}{|l|l|}
\hline Designation & GenBank accession \\
\hline Escherichia coli str.K-12 substr.MG1655 & NC_000913.2 \\
\hline Escherichia coli O157:H7 str.EDL933 & NC_002655.2 \\
\hline Escherichia coli O157:H7 str.Sakai & NC_002695.1 \\
\hline Escherichia coli UTI89 & NC_007946.1 \\
\hline Escherichia coli 536 & NC_008253.1 \\
\hline Escherichia coli APEC 01 & NC_008563.1 \\
\hline Escherichia coli HS & NC_009800.1 \\
\hline Escherichia coli E24377A & NC_009801.1 \\
\hline Escherichia coli ATCC 8739 & NC_010468.1 \\
\hline Escherichia coli str.K-12 substr.DH10B & NC_010473.1 \\
\hline
\end{tabular}

\begin{tabular}{|c|c|}
\hline Escherichia coli SMS-3-5 & NC_010498.1 \\
\hline Escherichia coli O157:H7 str.EC4115 & NC_011353.1 \\
\hline Escherichia coli SE11 & NC_011415.1 \\
\hline Escherichia coli O127:H6 str.E2348/69 & NC_011601.1 \\
\hline Escherichia coli IAI1 & NC_011741.1 \\
\hline Escherichia coli S88 & NC_011742.1 \\
\hline Escherichia coli 55989 & NC_011748.1 \\
\hline Escherichia coli IAI39 & NC_011750.1 \\
\hline Escherichia coli UMN026 & NC_011751.1 \\
\hline Escherichia coli LF82 & NC_011993.1 \\
\hline Escherichia coli BW2952 & NC_012759.1 \\
\hline Escherichia coli B str. REL606 & NC_012967.1 \\
\hline Escherichia coli O157:H7 str.TW14359 & NC_013008.1 \\
\hline Escherichia coli 0103:H2 str.12009 & NC_013353.1 \\
\hline Escherichia coli O26:H11 str.11368 & NC_013361.1 \\
\hline Escherichia coli O111: $\mathrm{H}$ - str.11128 & NC_013364.1 \\
\hline Escherichia coli SE15 & NC_013654.1 \\
\hline Escherichia coli DH1 & NC_017625.1 \\
\hline Escherichia coli 042 & NC_017626.1 \\
\hline Escherichia coli IHE3034 & NC_017628.1 \\
\hline Escherichia coli ABU 83972 & NC_017631.1 \\
\hline Escherichia coli ED1a & NC_017633.1 \\
\hline Escherichia coli O83:H1 str.NRG 857C & NC_017634.1 \\
\hline Escherichia coli NA114 & NC_017644.1 \\
\hline Escherichia coli O7:K1 str.CE10 & NC_017646.1 \\
\hline Escherichia coli O55:H7 str.CB9615 & NC_017656.1 \\
\hline Escherichia coli KO11FL & NC_017660.1 \\
\hline Escherichia coli $\mathrm{P} 12 \mathrm{~b}$ & NC_017663.1 \\
\hline
\end{tabular}

Table 7: List of assembled [20] E. coli genomes used in the design of $E$. coli-specific primers.

\section{Discussion}

Analysis of the present results according to patient sex, indicated that although, E. coli is the predominant isolated pathogen from both sexes, it occurred more frequently in females (50\% in females compared to $28.45 \%$ in males). E. coli showed the highest percentage of resistance to ampicillin, aztreonam, cefepime, ceftriaxone, cefuroxime, cephalothin, ceftazidime and amoxicillin. However, all isolates of E. coli were high susceptible to meropenem, imipenem, colistin, ertapenem and amikacin. For all UTI isolates E. coli , least resistance was observed against drugs such as Ciprofloxacin and Trimethoprim/Sulfamethoxazole. This study is comparable with the 
results reported by Astal and Sharif [21] and McIsaac et al. [22]. Based on the results of the present study, it was revealed that the susceptibility of bacteria to ciprofloxacin and other antibiotics were similar to many studies $[21,23]$.

E. coli isolates producing extended spectrum $\beta$-lactamases (ESBLs) were 90 (78.45\%). These isolates were identified as ESBL-producers by the double-disk synergy test and the E-test (AB Biodisc). Vercauteren et al. [24], showed that the E-test ESBL test with ceftazidime only detected $81 \%$ of ESBLs tested in their laboratory, compared to 97 and $91 \%$ for the double-disk test and the three-dimensional test, respectively. While Sanders et al. [25] showed that the Vitek ESBL test was $99 \%$ sensitive and specific for the detection of ESBLs. These data of the present study show that, by testing for ESBL results reported a significant number of ESBL producing E. coli strains as sensitive (S) or intermediate (I) for cefoxitin and resistant (R) or sensitive (S) and intermediate (I) for each of aztreonam, cefotaxime, ceftazidime and cefepime. The presence of an ESBL is suspected in Escherichia coli infections when resistance to one or more of the extended-spectrum cephalosporins (ESCs) (cefotaxime, ceftazidime, ceftriaxone or cefepime) is detected by [26-28]. In this study, the ESBL producing $E$. coli strains would have been reported as sensitive for cefoxitin (87.78\%), ceftazidime (46.67\%), cefepime (31.11\%) and for cefotaxime $(5.56 \%)$. But, as intermediate for ceftazidime $(21.11 \%)$, cefepime (18.89\%), cefoxitin $(12.22 \%)$, aztreonam $(8.89 \%)$ and for cefotaxime (2.2\%). Isolates were resistant for each of cefotaxime $(92.22 \%)$, aztreonam (74.44 \%) and cefepime (50\%) respectively. While, Kristo et al. [29], found that $6.4 \%$ of the ESBL producing strains were susceptible to cefotaxime, $44.6 \%$ to ceftazidime, and $55.4 \%$ to cefepime; as many as $71.8 \%$ were susceptible to at least one ESC. However, McWilliams et al. [30], recorded that E. coli isolates examined, $8.0 \%, 58.0 \%$ and $52.7 \%$ were called susceptible to cefotaxime, ceftazidime, and cefepime, respectively; All the isolates used during this study were also considered resistant to aztreonam, cefotaxime, and cefepime. But disk diffusion indicated susceptibility to cefoxitin. Cefoxitin is a cephamycin antibiotic often grouped with the second generation cephalosporins, is considered to be a strong $\beta$ lactamase inducer as are certain other antibiotics (such as imipenem), as reported by [31]. Paterson et al. [5] recorded that the cephamycins (cefoxitin, cefotetan and cefmetazole) are structurally different from the "true" cephalosporins and have enhanced stability to ESBLs. More than $90 \%$ of ESBL-producing organisms were "susceptible" to cephamycins. Tenover et al. [32] found that only $18 \%$ of laboratories correctly identified challenge organisms as potential ESBL producers using susceptibility to one or more expanded-spectrum $\beta$-lactam antibiotics as the method of detection. Changing patterns in microbial resistance suggest cefotaxime may be suffering greater resistance than ceftriaxone, whereas the two were previously considered comparable by Gums et al. [33].

PCR with oligonucleotide primers were used for detection of $T E M$, $S H V, C T X-M$ and $O X A$ genes and were carried out on DNA of 75 isolates of E. coli. A study by Grover et al. [34] on phenotypic and genotypic methods of ESBL detection concluded PCR. Four PCR products from different kinds of samples were sequenced during this study and reported as Saudi strains in Gen Bank (Accession Numbers: EF125011, AB282997, DQ303459 and L07945. Bradford [2] showed that easiest and most common molecular method used to detect the presence of a $\beta$-lactamase belonging to a family of enzymes is PCR with oligonucleotide primers that are specific for a $\beta$-lactamase gene. Oligonucleotide primers can be chosen from sequences available in public databases such as Genebank. These primers are usually chosen to anneal to regions where various point mutations are not known to occur. However, PCR will not discriminate among different variants of $T E M$ or $S H V$. Our molecular study revealed the ESBLs producing organisms contained $O X A(701 \mathrm{bp})$ was the main type of $\beta$-lactamase (35.7\%), CTX-M (569 bp) was second (28.9\%), TEM (403 bp) was third (20.5\%) and SHV (293 bp) (14.9\%) was fourth genes by PCR. While, Thabit et al. [4] found that, CTX-M was the main type of $\beta$ lactamases, followed by TEM, then $S H V$. Although, the PCR data of ESBL-producing strains revealed that blaCTX-M genes were the most frequent $E S B L$ types (74\%), followed by blaTEM (67\%) and finally blaSHV (45\%) respectively [35]. Bradford [2] recorded that the OXAtype enzymes are another growing family of ESBLs and it was originally created as a phenotypic rather than a genotypic group for a few $\beta$-lactamases that had a specific hydrolysis profile. Therefore, there is as little as $20 \%$ sequence homology among some of the members of this family. Although, these $\beta$-lactamases differ from the TEM and SHV enzymes in that they belong to molecular class D and functional group $2 \mathrm{~d}$ as reported by Thenmozhi et al. [7].

In several reports, the TEM gene has high frequency compared to $S H V$ gene $[36,37]$ but it was different compared to Taşli et al. [38] and Ramazanzadeh's [20] results.

In conclusion, the ESBL producing isolates detected PCR with oligonucleotide primers of TEM, SHV, CTX-M and $O X A$ genes and were carried out on E. coli DNA of 75 isolates. PCR, incorporating the primers for commonly prevalent ESBLs may be a valuable clinical and research tool for characterization of ESBLs. Moreover, detection of $T E M, S H V, C T X-M$ and $O X A$ genes gave a better understanding of ESBL production [10].

\section{Ethical Considerations}

- A consent to collect the samples is obtained from different hospitals and centers included in the study.

- Valid consent of the person under the study.

- Maintaining confidentiality of information obtained from subjects under the study.

- Complete information regarding risk factors is handed to all patients under the study and no concealment what so over.

- Results of samples collected are donated to all patients included in the study and some sample results were dispatched to physicians for treatment prescription.

\section{Acknowledgement}

The author thanks the University of Princess Noura bint Abdul Rahman for supporting the work.

\section{References}

1. Dias Neto JA, Martins ACP, da Silva LM, Tiraboschi RB, Domingos ALA, et al. (2003) Community acquired urinary tract infection: etiology and bacterial susceptibility. Acta Cir Bras 18.

2. Bradford P (2001) Extended-spectrum beta-lactamases in the 21st century: characterization, epidemiology, and detection of this important resistance threat. Clin Microbiol Rev 14: 933-951.

3. Hryniewicza K, Szczypab K, Sulikowskab A, Jankowskia K, Betlejewskab $\mathrm{K}$, et al. (2001) Antibiotic susceptibility of bacterial strains isolated from urinary tract infections in Poland. J Antimicro Chemotherapy 47: 773-780.

4. Thabit AG, El-Khamissy TR, Ibrahim MA, Attia AE (2011) Detection of extended-spectrum $\beta$-lactamase enzymes (esbls) produced by Escherichia 
coli urinary pathogens at assiut university hospital. Bull Pharm Sci Assiut University 34: 93-103.

5. Paterson DL, Ko WC, Von Gottberg A, Casellas JM, Mulazimoglu L, et al. (2001) Outcome of Cephalosporin Treatment for Serious Infections Due to Apparently Susceptible Organisms Producing Extended-Spectrum $\beta$ Lactamases: Implications for the Clinical Microbiology Laboratory. J Clin Microbiol 39: 2206-2212.

6. Ramphal R, Ambrose PG (2006) Extended-Spectrum b-Lactamases and Clinical Outcomes: current data. Clin Infect Dis 4: S164-S172.

7. Thenmozhi S, Moorthy K, Sureshkumar BT, Suresh M (2014) Antibiotic Resistance Mechanism of ESBL Producing Enterobacteriaceae in Clinical Field: A Review. Int J Pure App Biosci 2: 207-226.

8. Schmitt J, Jacobs E, Schmidt H (2007) Molecular characterization of extended-spectrum beta-lactamases in Enterobacteriaceae from patients of two hospitals in Saxony, Germany. J Med Microbiol 56: 241-249.

9. Qin X, Zerr DM, Weissman SJ, Englund JA, Denno DM, et al. (2008) Prevalence and Mechanisms of Broad-Spectrum _-Lactam Resistance in Enterobacteriaceae: a Children's Hospital Experience. Antimicrob Agents Chemother 52: 3909-3914.

10. Sharma M, Pathak S, Srivastava P (2013) Prevalence and antibiogram of Extended Spectrum $\beta$-Lactamase (ESBL) producing Gram negative bacilli and further molecular characterization of ESBL producing Escherichia coli and Klebsiella spp. J Clin Diagn Res 7: 2173-2177.

11. Wilson ML, Gaido L (2004) Laboratory Diagnosis of Urinary Tract Infections in Adult Patients. Clin Infect Dis 38: 1150-1158.

12. Behzadi P, Behzadi E, Yazdanbod H, Aghapour R, Akbari Cheshmeh M, et al. (2010) A survey on urinary tract infections associated with the three most common uropathogenic bacteria. Maedica (Buchar) 5: 111-115.

13. Forbes BA, Sahm DF, Weissfeld AS (2007) Bailey and Scott's Diagnostic microbiology. 12th edn, Elsevier, pp. 842-855.

14. MacFaddin JF (2000) Biochemical tests for identification of medical bacteria. 3rd edn, Lippincott Williams and Wilkins, Philadelphia.

15. Mandell GL, Bennett JE, Dolin R (2005) Principles and practice of infectious diseases. Churchill Livingstone, London, UK: pp. 881-882.

16. Kejela T, Bacha K (2013) Prevalence and antibiotic susceptibility pattern of methicillin-resistant Staphylococcus aureus (MRSA) among primary school children and prisoners in Jimma Town, Southwest Ethiopia. Ann Clin Microbiol Antimicrob 12: 11.

17. Queipo-Ortuño MI, de Dios Colmenero J, Macias M, Bravo MJ, Morata P (2008) Preparation of Bacterial DNA Template by Boiling and Effect of Immunoglobulin G as an Inhibitor in Real-Time PCR for Serum Samples from Patients with Brucellosis. Clin Vaccine Immunol 15: 293-296.

18. Clinical and Laboratory Standards Institute (2010) Performance standards for antimicrobial susceptibility testing; 20th informational supplement. CLSI document M100-S20. Clinical and Laboratory Standards Institute, Wayne, Philadelphia.

19. Clinical and Laboratory Standards Institute (2014) Performance standards for antimicrobial susceptibility testing; 21st informational supplement. CLSI document M100-S24. Clinical and Laboratory Standards Institute, Wayne, PA, USA.

20. Ramazanzadeh R, Farhadifar F, Mansouri M (2010) Etiology and antibiotic resistance pattern of community-acquired extended-spectrum beta-lactamase-producing gram negative isolates in Sanandaj. Res J Med Sci 4: 243-247.

21. Astal ZY, Sharif FA (2002) Relationship between demographic characteristics and community-acquired urinary tract infection. East Mediterr Health J 8: 164-171.

22. McIsaac WJ, Mazzulli T, Moineddin R, Raboud J, Ross S (2004) Uropathogen antibiotic resistance in adult women presenting to family physicians with acute uncomplicated cystitis. Can J Infect Dis Med Microbiol 15: 266-270.
23. Gupta K, Hooton TM, Stamm WE (2001) Increasing antimicrobial resistance and the management of uncomplicated community acquired urinary tract infections. Ann Intern Med 135: 41-50.

24. Vercauteren E, Descheemaeker P, Leven M, Sanders CC, Goossens H (1997) Comparison of screening methods for the detection of extendedspectrum $\beta$-lactamases and their prevalence among blood isolates of Escherichia coli and Klebsiella spp. in a Belgian teaching hospital. J Clin Microbiol 35: 2191-2197.

25. Sanders CC, Barry AL, Washington JA, Shubert C, Moland ES, et al. (1996) Detection of extended spectrum $\beta$-lactamase producing members of the family Enterobacteriaceae with the Vitek ESBL test. J Clin Microbiol 34: 2997-3001.

26. Cheng J, Ye Y, Wang YY, Li H, Li X, et al. (2008) Phenotypic and molecular characterization of 5 novel CTX-M enzymes carried by Klebsiella pneumoniae and Escherichia coli. Acta Pharmacol Sin 29: 217-225.

27. Coudron PE, Moland ES, Sanders CC (1997) Occurrence and detection of extended-spectrum $\beta$-lactamases in members of the family Enterobacteriaceae at a veterans medical center. J Clin Microbiol 35: 2593-2597.

28. Cormican MG, Marshall SA, Jones RN (1996) Detection of extendedspectrum $\beta$-lactamase (ESBL)-producing strains by the E-test ESBL screen. J Clin Microbiol 34: 1880-1884.

29. Kristo I, Pitiriga V, Poulou A, Zarkotou O, Kimouli M, et al. (2013) Susceptibility patterns to extended-spectrum cephalosporins among Enterobacteriaceae harbouring extended-spectrum _-lactamases using the updated Clinical and Laboratory Standards Institute interpretive criteria. Int J Antimicrob Agents 41: 383-387.

30. McWilliams CS, Condon S, Schwartz RM, Ginocchio CC (2014) Incidence of Extended-Spectrum- $\beta$-Lactamase-Producing Escherichia coli and Klebsiella pneumoniae Isolates. That Test Susceptible to Cephalosporins and Aztreonam by the Revised CLSI Breakpoints. J Clin Microbiol 52: 2653-2655.

31. Phillips I, Shannon K (1993) Importance of beta-lactamase induction. Eur J Clin Microbiol Infect Dis 12: S19-S26.

32. Tenover FC, Mohammed MJ, Stelling J, O'Brien T, Williams R (2001): Ability of laboratories to detect emerging antimicrobial resistance: proficiency testing and quality control results from the World Health Organization's external quality assurance system for antimicrobial susceptibility testing. J Clin Microbiol 39: 241-250.

33. Gums JG, Boatwright DW, Camblin M, Halstead DC, Jones ME, et al. (2008) Differences between ceftriaxone and cefotaxime: microbiological inconsistencies. Ann Pharmacother 42: 71-79.

34. Grover SS, Sharma M, Chattopadhya D, Kapoor H, Pasha ST, et al. (2006) Phenotypic and genotypic detection of ESBL mediated cephalosporins resistance in Klebsiella pneumoniae: Emergence of high resistance against cefepime, the fourth generation cephalosporins. J Infect 54: 279-288.

35. Seyedjavadi SS, Goudarzi M, Sabzehali F (2016) Relation between blaTEM, blaSHV and blaCTX-M genes and acute urinary tract infections. J Acute Disease 5: 71-76.

36. Herna'ndez JR, Martı'nez-Martı'nez L, Canto'n R, Coque TM, Pascual A (2005) Nationwide study of escherichia coli and Klebsiella pneumoniae producing extended-spectrum -lactamases in Spain. Antimicrob Agents Chemother 49: 2122-2125.

37. Shahcheragh F, Nasiri S, Noveiri H (2009) Detection of extendedspectrum $\beta$-lactamases (ESBLs) in Escherichia coli. Iran J Clin Infect Dis 4: 63-70.

38. Taşli H, Bahar IH (2005) Molecular characterization of TEM and SHV derived extended-spectrum beta-lactamases in hospital-based Enterobacteriaceae in Turkey. Jpn J Infect Dis 58: 162-167. 